\title{
A Batalha pela memória: o papel dos anarquistas nas Revoluções Russa e Ucraniana Davi Luiz Paulino
}

DOI: 10.11606/issn.2318-8855.v8i8p236-243

Resumo: A presente resenha tem por objetivo abordar a obra Os Anarquistas Russos, os Sovietes e a Revolução de 1917, de Alexandre Skirda, propondo inseri-la no debate historiográfico acerca das Revoluções Russa e Ucraniana e tratando, principalmente, do papel desempenhado pelos anarquistas e suas referidas organizaç̃os. Partindo disso, o autor analisará temas como o desenvolvimento das comunidades camponesas russas sob o regime czarista, a constituição do pensamento anarquista e a referida atuação dos libertários durante as revoluções. O livro de Skirda dialoga com a historiografia tradicional sobre a Revolução Russa, propondo um novo olhar para atuação dos diversos grupos que participaram desse processo e amparando-se metodologicamente, a nosso ver, na concepção braudeliana de História, preocupada em compreender o impacto das estruturas de longa duração no contexto revolucionário, ao mesmo tempo em que aborda a ação dos trabalhadores e camponeses.

*Graduado em História pela Pontifícia Universidade Católica de São Paulo. Contato: davi.paulino92@gmail.com 


\section{resenhas}

\section{A Batalha pela memória: o papel dos anarquistas nas Revoluções Russa e}

Ucraniana

SKIRDA, Alexandre. Os Anarquistas Russos, os Sovietes e a Revolução de 1917. Tradução: Plínio Augusto Coelho. São Paulo: Intermezzo Editorial, 2017. 384 p.

No período que marcou o centenário da Revolução Russa e Ucraniana de 1917, apareceram inúmeras obras com o intuito de atualizar o debate acerca desse processo, contribuindo para resoluções de questionamentos e combate a preconceitos sobre o acontecimento no Leste da Europa.

É nesse contexto que a Intermezzo Editorial, junto com o Instituto de Estudos Libertários e o Centro de Cultura Social de São Paulo, editaram a obra Os Anarquistas Russos, os Sovietes e a Revolução de 1917, do historiador ucraniano Alexandre Skirda. Filho de pai ucraniano e de mãe russa, o autor, nascido em 1942, tem estudos sobre a História do Anarquismo que variam das experiências russa e ucraniana quanto em análises mais globais do movimento libertário. Dentre as obras, ressaltamos Autonomie individuelle et force collective, les anarchistes et l'organisation de Proudhon à nos jours, que faz um profundo balanço histórico das experiências anarquistas desde Pierre-Joseph Proudhon até sua publicação em 1987.

O livro de Skirda nos remete a pensar a História da Revolução Russa em uma perspectiva braudeliana, ou seja, a partir da experiência da longa duração, dado que o autor parte, intencionalmente ou não, de uma análise das estruturas seculares da sociedade russa, mostrando suas permanências no decorrer do processo estudado por ele.

Essa perspectiva metodológica fica mais evidente quando nos deparamos com o primeiro capítulo - As tradições democráticas e igualitárias da Rússia antiga - que não 


\section{resenhas}

Davi Luiz Paulino

busca um retorno ao passado'. dito igualitário, mas sim mostrar que essas características estariam presentes no contexto da Revolução de 1917. Alexandre Skirda não constrói um julgamento do passado: sua concepção de história se aproxima de Olivier Dumoulin, que apresenta o ofício historiográfico como tendo "por dever desmistificar, e é nisso que os trabalhos históricos trazem sua contribuição para o debate cívico e constituem uma necessidade." (DUMOULIN, 2017, p. 41)

Continuando a abordagem ao primeiro capítulo, percebemos como o historiador segue seu estudo aprofundando a análise das tradições democráticas russas. Primeiramente, investiga os fundamentos da estrutura da vetche $e^{2}$ e como sua função garantia uma perspectiva democrática à população, dado que "todos os problemas fundamentais eram submetidos à vetche, particularmente a eleição do príncipe." (SKIRDA, 2017, p. 15)

Outra forma organizacional abordada pelo autor é o $\mathrm{mir}^{3}$ que, segundo ele, deu aos camponeses a liberdade para tratar de seus próprios negócios e até mesmo a livre associação entre suas comunas.

Skirda insere o mir na conjuntura czarista da Rússia da seguinte forma:

Com efeito, nesse império repousando sobre a servidão de sua população, subsistia uma estrutura social e econômica autônoma no mundo camponês, fundado sobre a posse coletiva da terra, a obchtchina, e a partilha dos produtos do trabalho comum; isso sobre a base de uma autoadministração coletiva dos membros do mir, palavra tendo uma tripla significação bem simbólica em russo: "comuna", "paz" e "mundo". (SKIRDA, 2017, p. 29)

A significação simbólica que o autor estabelece para essa organização elucida sua

\footnotetext{
${ }^{1}$ Eric Hobsbawm em seu Era dos Extremos parte da concepção de que os anarquistas russos queriam um retorno a Rússia do medievo, tese que foi refutada por Skirda no seu livro.

${ }^{2}$ A vetche assemelhava-se a uma assembleia que abarcaria todos os membros da cidade.

${ }^{3}$ Mir corresponde à comuna.
} 


\section{resenhas}

\section{A Batalha pela memória: o papel dos anarquistas nas Revoluções Russa e}

Ucraniana

importância para a sociabilidade do campesinato russo, que se ancorava na autonomia das comunas. O autor esclarece também que historiadores próbolchevique, como Eric Hobsbawm, entendiam que a manutenção da pequena propriedade pelos camponeses representava uma prática pequeno-burguesa que seria rompida a partir da aliança com o operariado, sendo este um genuíno agente revolucionário. Entretanto, ele mostra que a base organizativa do mir preconizava a posse coletiva da terra, portanto, ela pertencia à aldeia/comunidade trabalhada por todos os membros da comuna.

O caráter de participação coletiva tanto na vetche quanto no mir esteve presente nas lutas dos trabalhadores nas revoluções de 1905 e 1917, principalmente na organização dos sovietes (conselhos), que não eram diretamente "fruto de geração espontânea, eles não emanavam do nada, eram só a forma urbana do mir mais adaptada a uma nova situação." (SKIRDA, 2017, pp. 54-55)

O campesinato continua sendo objeto de reflexão no segundo capítulo da obra, mas dessa vez o autor o aborda a partir do anarquismo russo desde Bakunin a 1917. Mikhail Bakunin enxergava no camponês um enorme potencial libertário que contribuiria para a revolução social e poria fim ao burocratismo czarista. Skirda demonstra que, para os anarquistas, as comunas camponesas não poderiam permanecer isoladas, mas deveriam conectar-se aos esforços dos operários urbanos, ou seja, se ancorariam em bases federalistas.

Os anarquistas, em uma perspectiva de longa duração, pensavam a reorganização da nova sociedade a partir das permanências do mir e proporiam a economia repousada sobre unidades de produção, a indústria estaria ligada com a agricultura e a produção com o consumo. Essas seriam as bases do comunismo libertário de matriz 
Davi Luiz Paulino

kropotkiana.

O autor aponta que esses princípios anarquistas garantiram ao movimento um constante crescimento entre as massas:

O movimento conhece um crescimento exponencial: em 1903, há 12 organizações em 11 cidades; em 1904, 29 grupos em 27 lugares de habitação do Noroeste, do Sudeste e Sul do país; em 1905, há 125 grupos e federações em 110 cidades e localidades; em 1906, 221 em 155 cidades, e em 1907, apogeu do movimento, 255 formações em 180 localidades. No total, durante o período 1903-1910, a ação dos anarquistas manifesta-se em 218 locais de habitação, 51 governos e 7 regiões recobrindo os três quartos do império. Federações coexistem com grupos e círculos, agrupando respectivamente várias centenas e várias dezenas de membros. Há três centros importantes: Bialystock, Odessa e Ekaterinoslav; mas grupos e federações recobrem o conjunto do império. (SKIRDA, 2017, p. 67)

O apontamento feito por Skirda contribui para rompermos com a perspectiva de que o movimento anarquista na Rússia não tinha importância entre as organizações de classe e também com a perspectiva de que o próprio movimento não teria organização. São esses militantes anarquistas que estarão presentes junto aos trabalhadores nas Revoluções Russa e Ucraniana.

Outra contribuição desse capítulo é refletir sobre o papel dos anarquistas nos processos de 1917, dado que obras clássicas da historiografia com pretensões à imparcialidade acabam por colocar as ações revolucionárias como obra de um único agrupamento ${ }^{4}$.

O processo de 1917 contou com a participação anarquista. Segundo Alexandre Skirda houve, nas vésperas da revolução, 40 organizações libertárias espalhadas por 21 cidades que representavam aproximadamente 40.000 militantes. Os

\footnotetext{
${ }^{4}$ CARR, Edward Hallet. The Bolshevik Revolution: 1917-1923. 3vols. New York: W. W. Norton \& Company, 1985. O título já contesta a abordagem imparcial proposta pelo próprio autor.
} 


\section{resenhas}

\section{A Batalha pela memória: o papel dos anarquistas nas Revoluções Russa e}

Ucraniana

anarcossindicalistas tinham força em comitês de fábricas e usinas, sindicatos de padeiros, metalúrgicos, e estivadores; pregavam aos trabalhadores o controle direto dos meios de produção, partindo de uma organização pela base e não através do Estado, mesmo o de roupagem proletária.

É nesse embate entre o anti-estatismo e estatismo que Skirda adentra o terceiro capítulo em que analisa a confrontação dos bolcheviques com os anarquistas. O historiador alega que o conflito estabeleceu-se em torno da questão Estado/Comuna, já que os anarquistas preconizavam a construção da nova sociabilidade a partir das comunas de sovietes autogovernadas e federadas entre si, e os bolcheviques prezavam pela organização do Estado proletário.

A questão do controle operário é amplamente trabalhada pelo autor, passando pelas diferentes concepções. Ele aponta que os anarquistas lutaram pela autonomia das massas e a organização autogestionária da produção pelos conselhos de fábricas e usinas, enquanto os bolcheviques acreditavam que o atraso socioeconômico do país só poderia ser solucionado por uma centralização da produção por meio do Estado, que resultou por minar a autonomia dos trabalhadores em relação às decisões.

A partir desse antagonismo, o autor mostra que tem início uma campanha de difamações contra os anarquistas com intuito de denegrir a imagem do movimento libertário, legitimando assim a política bolchevique. O adjetivo "anarcobandido" começou a ser disseminado na literatura bolchevique, as organizações anarquistas começaram a serem taxadas de contrarrevolucionárias e perseguidas e até a experiência autogestionária da Makhnovtchina foi acusada de se aliar aos grandes proprietários de terras (Kulaks) e as potências estrangeiras com o intuito de por fim a 


\section{resenhas}

\section{Davi Luiz Paulino}

revolução, calúnia refutada por Skirda em sua obra.

A posição dos anarquistas em relação aos bolcheviques era "eliminar da terra a ordem da comissariocracia e das tchecas e instaurar uma livre federação panrussa de uniões de trabalhadores e das massas oprimidas." (SKIRDA, 2017, p. 108)

Com essa definição chegamos ao último capítulo do texto de Alexandre Skirda, que aborda a hegemonia do Partido Bolchevique sob os trabalhadores do campo e da cidade. Para ele, as tradições dos camponeses e operários que se ancoravam na questão da coletividade foi suprimida pelo partido que, a partir de então, passou a definir em uma cúpula de revolucionários profissionais os rumos das massas na edificação do "Estado proletário", que Skirda denominou Partidocracia. Cabe ressaltar que o autor expõe um pensamento profundo acerca das lições da experiência anarquista na Revolução de 1917, demonstrando que ela contribuiu para por em evidência as práticas libertárias que já eram oriundas das massas, deixando aos anarquistas justamente o papel de manter vivas essas concepções.

Para concluir, é necessário dizer que a obra de Alexandre Skirda não termina em seu texto. Ele reuniu diversos documentos e testemunhos que representam metade do livro; nessa parte, podemos ter acesso a resoluções propostas pelos grupos anarcossindicalistas, a denúncias da repressão bolchevique que os anarquistas sofriam, a diversos textos que abordam grandes experiências autogestionárias como Kronstadt e à Makhnovtchina, além de comentários de autores clássicos do anarquismo russo e internacional sobre essa experiência, nos deixando contribuições importantes para pensar a revolução social, a autogestão e também seus problemas.

Alexandre Skirda não encerra uma análise; pelo contrário, seu texto é 


\section{resenhas}

A Batalha pela memória: o papel dos anarquistas nas Revoluções Russa e Ucraniana justamente a abertura para estudos futuros que contribuam para evidenciar uma história que foi escamoteada e difamada ao longo dos anos. Esse é um dos maiores méritos do autor.

\section{Referências Bibliográficas}

BRAUDEL, Fernand. Escritos sobre a História. Tradução de J. Guinsburg e Tereza Cristina Silveira da Mota. São Paulo: Perspectiva, 2014.

CARR, Edward Hallett. The Bolshevik Revolution: 1917-1923. 3vols. New York: W. W. Norton \& Company, 1985.

DUMOULIN, Olivier. O papel social do historiador: da cátedra ao tribunal. Tradução: Fernando Scheibe. Belo Horizonte: Autêntica, 2017.

HOBSBAWM, Eric. A Era dos Extremos: o Breve Século XX: 1914-1991. Tradução: Marcos Santarrita. São Paulo: Companhia das Letras, 2016.

SKIRDA, Alexandre. Os Anarquistas Russos, os Sovietes e a Revolução de 1917. Tradução: Plínio Augusto Coelho. São Paulo: Intermezzo Editorial, 2017. 